\title{
Research on intelligent information sharing system of scientific research based on cloud technology
}

\author{
HuYanni
}

\author{
Wuhan Institute of Shipbuilding Technology, Wuhan 430050,China
}

Key words: local universities; research information; cloud technology; sharing system

\begin{abstract}
In this paper, in order to achieve intelligent scientific information sharing of local universities as a starting point, the characteristics of cloud technology and the sharing requirements of scientific information resources has been analyzed. Using cloud technology to manage local scientific research information, intelligent sharing system of scientific information based on cloud technology has been designed. This system can store, exchange and share the scientific information in Colleges and universities, the local science and technology management department, the school scientific research management department, department level scientific research department, the financial department and the School researchers can get accurate scientific information more convenient.
\end{abstract}

\section{Introduction}

In the local colleges and universities, most of the scientific management system is simple to scientific research project of the personnel information, spending, project type, results of data storage and summary, lack of scientific information sharing and communication among colleges and universities. However, it is difficult for local science and technology management departments to grasp the latest scientific research information timely and dynamically, which affects the scientific nature of scientific research management decision-making. Therefore, the design of a stressed and dynamic process of scientific research management, service oriented, the local science and technology management department, the school scientific research management department, department level scientific research department, the financial department and the School researchers can get accurate scientific information more convenient to research information sharing system is particularly important.

\section{Cloud technology}

Cloud technology is the Internet era a new integrated technology, which is according to the demand, in the wide area network in computer software and hardware, network and router integration using, for example, the use of cloud computing technology, large amount of computational complexity of the program is divided into a plurality of subroutines, and then to the huge system consisting of multiple servers the calculation and analysis, and finally returns the results to the user.

With the rapid development of Internet and computer technology, the simple cloud technology has been everywhere, such as Baidu, Google and other search engines and web mail, users only need to input the keyword search information can be obtained. Cloud computing technology is the use of distributed, parallel, network, data mining, data processing and safe handling of combining a variety of ways, the use of unified planning background can be configured server resources, through the complex computation, reasoning, analysis of the results obtained after the customer needs and sends the result to the user. The cloud has the advantage of saving the enterprise based software and 
hardware cost, shorten the product development cycle, and enhance the ability of data processing, processing with high efficiency on vast amounts of information in a short time. Because of the powerful computing efficiency of cloud technology, the processing and analysis of big data and mass information will be based on this technology. The framework of the cloud technology system is shown in Figure 1.

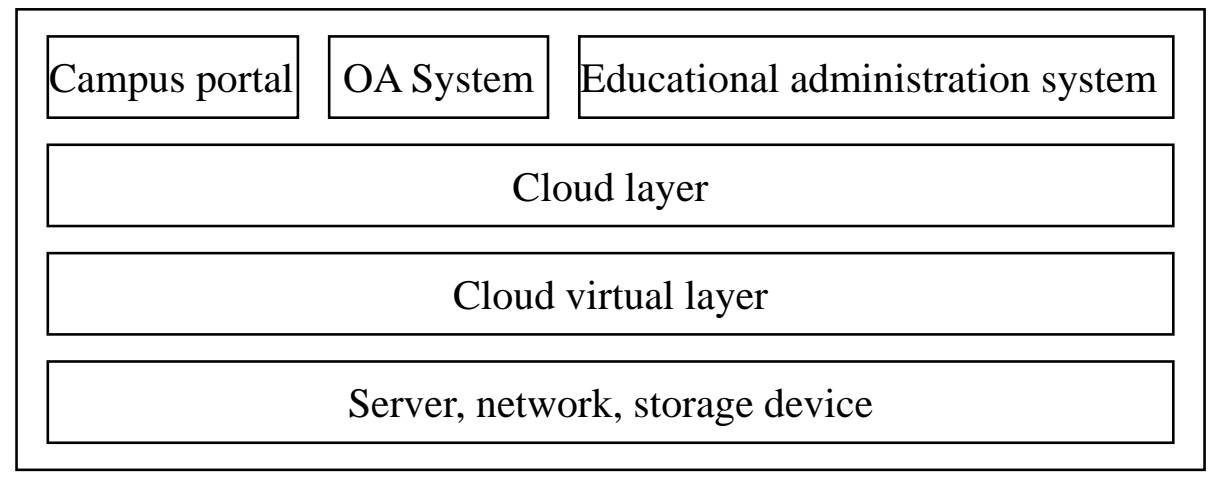

Fig. 1 The framework diagram of cloud technology system

\section{Sharing requirements of scientific research information resources}

The research project is a target that in order to perform in a specific time, budget and resources within the defined, and a series of complex and unique activities must be carried out, but in the process of research involves some professional researchers and various information resources. Among them, resource information is an important factor in the smooth completion of scientific research projects. In general, information resources mainly includes parts: one part is the scientific research personnel from the initial project to some external data, eventually concluding such as professional books, research papers, learning platform, patent literature information, also including the school science and technology part of the project application guide description, project application data and information; one part is some information resources generated in the process of research, mainly used to research, such as in response to the project, the project research innovation, project time and cost, in academic journals published papers, patents and other information resources. Scientific research information needed by researchers mainly includes the following four aspects:

(1) In addition to common points, the information of each research project also has its own personalized part: the declaration of scientific research project must be familiar with the application requirements of the project issued by the state, province and university. Must consult the progress and achievements of a large number of domestic and foreign research in the writing project declaration, in the process of project implementation, according to the research results of academic papers written and published, which belongs to the common point; in addition, the research way of cultural science and engineering research projects in different scientific research workers according to their own needs to carry out the work, the characteristics of belong to the individual.

(2) In the research summary of the project, the demand of the scientific research workers has changed greatly. The process that the scientific research project needs to experience is: Declaration and project approval, designated research plan, implementation, control and conclusion. In different stages of the project progress, the resource information needs will be changed due to the content of implementation is not the same. In the initial stage, is mainly a lot of reading and reporting topic related literature, and determined to declare the project innovation according to the technology itself, resource information needs at this stage is new in order to be different in the process of project implementation; however, the demand of information will become a very narrow range of 
knowledge, strong side; finally in control and the concluding step, only according to the need of research to prepare project completion materials.

(3) The information requirements of different levels of scientific research workers vary greatly: University researchers can be divided into several levels according to their research subjects, age and titles. In the application of the project, the scientific research workers who have no experience in the project should first understand how the project should choose the topic and how to combine their own research advantages to write the declaration and other basic information. The research workers who have the experience of project management will focus on familiar and topic related academic papers, research methods and social needs.

(4) The resources and information needs are different from each other with different roles: in the course of this project, each worker's role is not the same, the division of labor is different, therefore, resource information with their needs will vary greatly. The research project leader mainly manages and coordinates the research member, the cost, the time and so on information. Project members are gaining information according to their own division, such as technology researchers is mainly responsible for the project implementation, test and improvement work, the resource information needs related to the acquisition of information technology.

\section{Construction of intelligent sharing system of scientific research information based on cloud technology}

Overall architecture of the system. The overall structure of the intelligent sharing system of scientific research information plays an important role in its function application and management efficiency. The system is composed of foreground application and background maintenance, and its overall architecture is shown in Figure 2. 

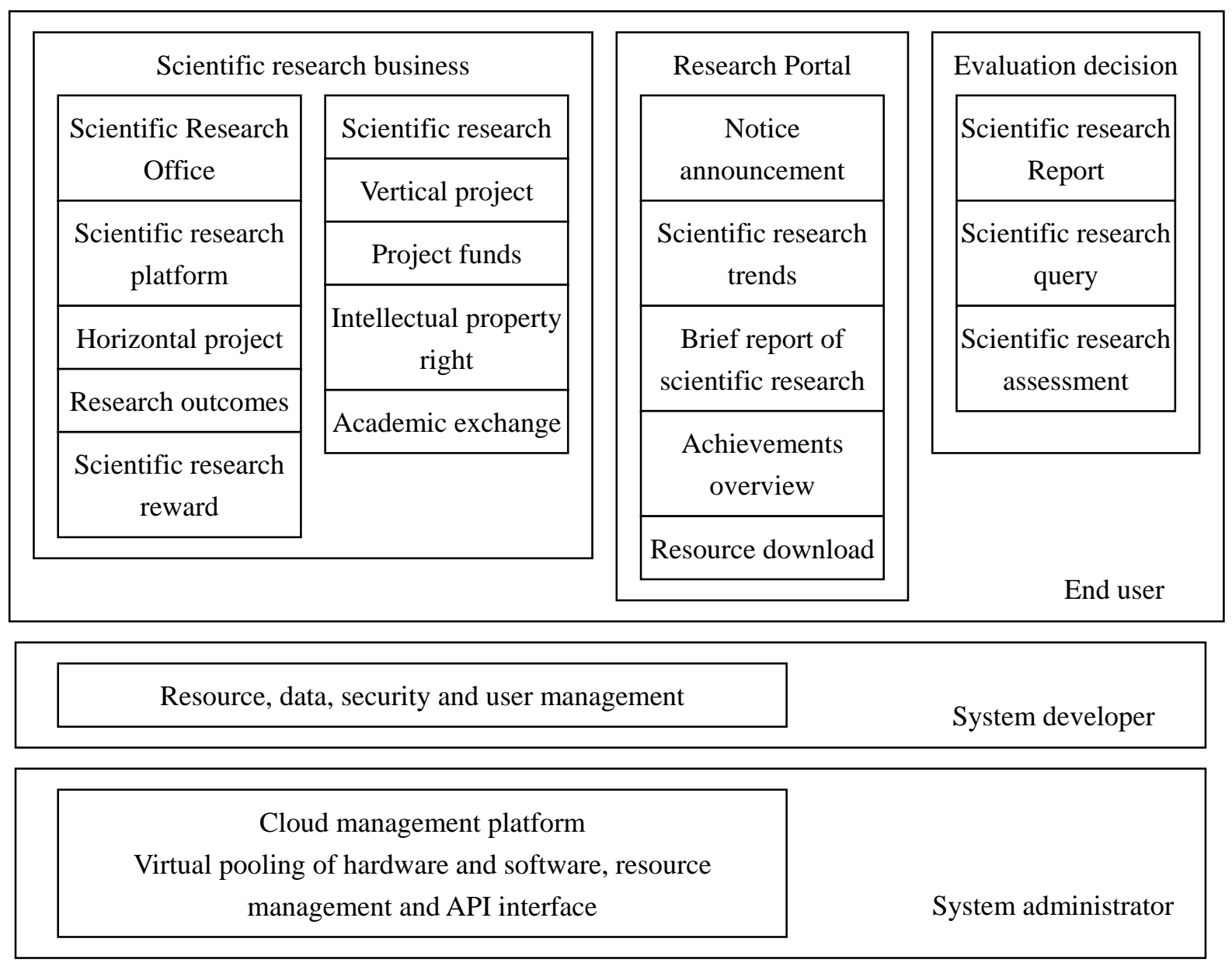

Fig. 2 overall framework of intelligent sharing system for scientific research information

The function of foreground application module. The application sharing system includes local science and technology management department users, the school scientific research department users, department level scientific research department users, the school Finance Department users and scientific researchers users five important local scientific research information intelligent management module.

(1) User management unit of local science and technology management department

This module is mainly to facilitate local science and technology management department staff to supervise the project all schools, so it can always understand the progress of scientific research projects, each project data query information, to provide reference information for the local science and Technology Bureau to develop scientific research policy.

(2) User management module of school scientific research department

The module user is the staff of each school's scientific research management department. The management of scientific research projects for the scientific research management is responsible for all the teachers and students, the management of scientific research personnel, project, progress, achievements and development of academic lectures and other information, and is responsible for the maintenance and management of the scientific research information sharing system.

(3) User management module of department level scientific research department

The module for user departments responsible for the progress of scientific research, scientific research units of the responsible person can query the research project, and to research the data information of the Faculty of statistics and analysis; on the research unit of the staff, the progress of the project, the use of funds, papers and patents, awards and achievements etc. the academic 
activities of management, in addition, also can carry out assessment and evaluation stage of research projects through the management module.

(4) User management module of school financial department

The users of the module are used by the school financial management personnel, which can monitor the use of funds through the system online. Through the pipeline module, the financial management personnel can real-time understand the use of funds for scientific research projects in the whole school, can directly record the expenditure on the management of the funds.

(5) User management module of scientific researchers

This module provides for researchers to use, researchers can conduct online management of project funds, achievements and rewards, you can apply for the business, scientific research project management system, check knot data, can view the relevant scientific research policy, dynamic information.

The function of background maintenance module. The background maintenance of intelligent sharing system of scientific research information is actually the system administrator work platform, and it is the super user of the whole system. The responsibility of the system administrator is to maintain and manage the parameter data of the system, and assign the accounts and permissions of other user layers. The system administrator has the highest management authority of the system, can add, delete, change, check, import and export data, manage system log, set system parameters and other operations on the system background data information. The main functions are as follows:

(1) New user account registration

All other users account for unified registration management, for different roles of users allocation permissions.

(2) Notice announcement management

According to the school document release notice or scientific research management information and other announcements.

(3) Message management

Receive and send scientific research information, and deal with the suggestions or opinions put forward by customer service.

(4) Data maintenance management

Add, delete, modify, check, import and export data, manage system log, set system parameters and so on.

\section{Conclusion}

The intelligent sharing system of scientific research information studied in the paper can supervise the scientific research information among local colleges and Universities. The system through cloud technology to store, exchange and the sharing of scientific information, so the local science and technology management department, the school scientific research management department, department level scientific research department, the financial department and the School scientific researchers can get full accurate scientific information more conveniently, which can realize the integration of personal scientific research information management and discipline group of research and information management, so as to realize the information sharing across disciplines of scientific research, which is the basis of the construction of experimental platform provide high quality information service and scientific research resources sharing for scientific research personnel in Colleges and universities. 


\section{Acknowledgements}

The work was supported by the scientific research project of Hubei Provincial Education Department in 2017 with the project number B2017511 and the project name Design of Expert System for Electrical Research Information in Higher Vocational Colleges.

\section{References}

[1] Wang Jian, Wu Dingfeng. Research on the mode of co construction and sharing of agricultural research information resources from the perspective of big data [J]. Chinese Agricultural Science Bulletin,Vol.33 (11), (2017), p.147-152.

[2] Liu Yarong. Problems and Countermeasures in the management of scientific research funds in Colleges and universities [J]. Journal of Jinzhong University, Vol.33 (05), (2016), p.51-53.

[3] Jiang Xiaohua. Importance and construction of information resource sharing in scientific research management in Colleges and universities[J]. Office Operations, No.13, (2016), p.137-138.

[4] Du Chunzhou. Management information sharing system of scientific research funds based on five tier architecture [D]. Guizhou University, (2015).

[5] Li Junjie, Luo Mengmeng. Problems and Countermeasures of university liberal arts research information sharing mechanism [J]. Journal of Lishui University, Vol.37 (01) , (2015), p.86-91.

[6] Zhan Zongbing, Fan Tinglu, Qin Chunlin, Yang Bochao. Design and implementation of scientific research information management platform of Gansu Academy of Agricultural Sciences Based on Web [J]. Gansu Agricultural Science and Technology, No.10, (2014), p.36-38.

[7] Lv Jinmei. Design and development of university scientific research management information system [D]. Zhengzhou University, (2014).

[8] Pan Hua, Yin Zhi. The application of cloud storage in the construction of digital resources in Colleges and universities [J]. China New Telecommunications, Vol.15 (23) , (2013), p.93-94.

[9] Yan Shuting, Liu Jiaxin. Study on mechanism of foreign information sharing in university scientific research management system[J]. Science and Technology Management Research,Vol.33 (12), (2013), p. 85-87,103.

[10] Han Lijuan. Research and design of scientific research management system based on C/S architecture [J]. Science Mosaic, No.05, (2013), p.121-123.

[11] Liu Hong, Wu Lijuan. Design and development of information management system for university teachers [J]. Journal of Shenyang Normal University(Natural Science Edition), Vol.30 (02), (2012), p.196-199.

[12] Xue Ping. Discussion on informatization construction of scientific research management in Higher Vocational Colleges [J]. Journal of Huaihai Institute of Techology (Humanities \& Social Science Edition), Vol.22 (9), (2011), p.112-114.

[13] Lang Qing. Research and design of scientific research management information system in agricultural and forestry universities [D]. Zhejiang agriculture and Forestry University, (2011). 
